\title{
ESTUDIO PARA LA ELABORACIÓN DE COMPOTAS PARA BEBÉS A PARTIR DE DURAZNO ENRIQUECIDO CON MACA, QUINUA, KIWICHA Y CAÑIHUA
}

Horacio Aldana Minaya, Ricardo Rivas Romero*

Universidad de Lima

Recibido: 4 de abril del 2018 / Aprobado: 29 de agosto del 2018

doi: 10.26439/ing.ind2019.nc37 4549

RESUMEN: El presente artículn expone los resultados de una investigación para el desarrollo de una compota para bebés a partir de durazno, enriquecida con maca, quinua, kiwicha y cañihua, el cual es un alimento complementario para el bebé rico en vitaminas, proteínas y minerales, cuyo consumo es a partir de los seis meses de edad. Al final del estudio se concluye que el proyecto es factible técnicamente.

Palabras clave: compota / alimentos para bebés / durazno / maca / quinua / kiwicha / cañihua

\section{A STUDY TO PREPARE BABY PEACH PURÉE ENRICHED WITH MACA, QUINOA, KIWICHA AND CAÑIHUA}

ABSTRACT: This article presents the results of a research aimed at preparing a baby peach purée enriched with maca, quinoa, kiwicha and cañihua. This fruit purée is a complementary food rich in vitamins, proteins and minerals for babies from 6 months of age. At the end of the study, it is concluded that the project is technically feasible.

Keywords: fruit purée / baby food / peach / maca / quinoa / kiwicha / cañihua

*20090027@aloe.ulima.edu.pe, ricardorivas21@outlook.es 


\section{PROBLEMÁTICA}

Para el desarrollo del Perú no basta con tener recursos naturales, también es necesario tener un capital humano preparado, tanto física como intelectualmente, para enfrentar los retos futuros. Es por ello que esta investigación se concentra en el desarrollo de un alimento para una etapa esencial de la vida, como es la nutrición en la infancia, pues ahí se da el crecimiento y maduración cerebral, además de la multiplicación neuronal. La exposición a procesos prolongados de desnutrición en la infancia puede ocasionar deficiencias permanentes en el desarrollo, además de rezago intelectual. En la búsqueda de soluciones a este problema de desnutrición nace este proyecto, en el cual se busca rescatar los conocimientos ancestrales de los incas sobre granos andinos y combinarlos con tecnología de punta para ofrecer un alimento rico en vitaminas y proteínas para los infantes (Concha Pacheco, 1989; Mendoza Flórez, 1994).

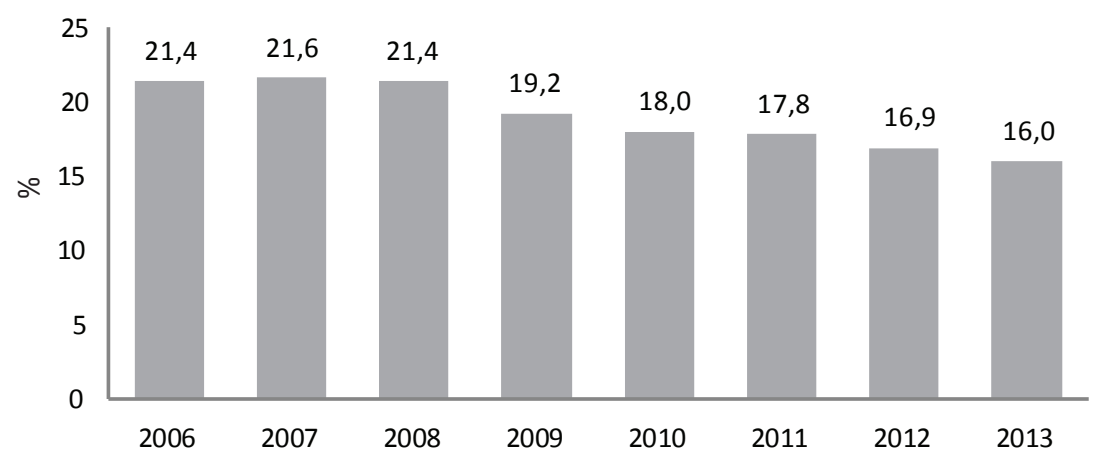

Figura 1. Perú: Proporción de menores de cinco años con desnutrición crónica, según patrón de referencia NCHS del 2006 al 2013

Fuente: INS, 2014

La desnutrición es un obstáculo al desarrollo humano y reduce las posibilidades de desarrollo económico de los países

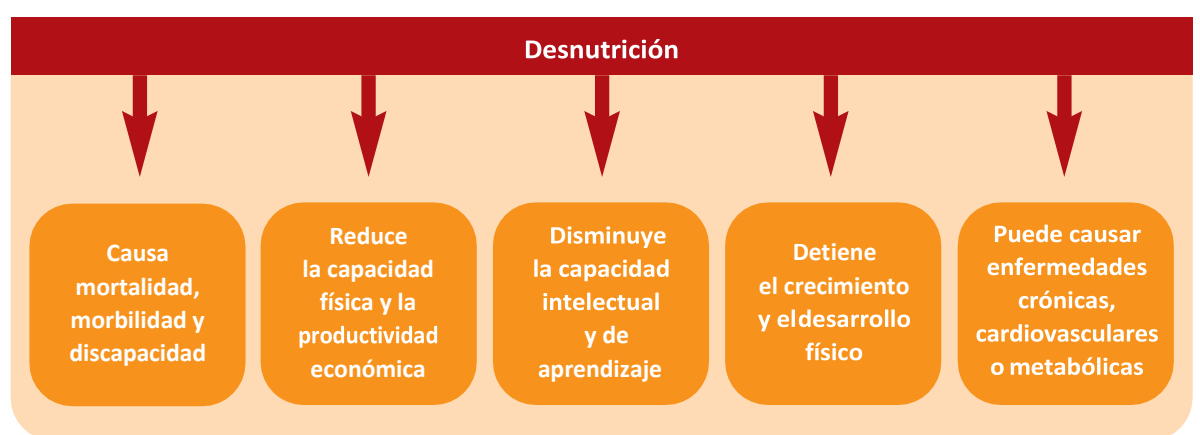

Figura 2. Consecuencias de la desnutrición infantil Fuente: UNICEF, 2011 


\section{CARACTERÍSTICAS DEL PRODUCTO}

El producto final es una compota para bebés a partir de durazno enriquecido con maca, quinua, kiwicha y cañihua el cual es un alimento rico en vitaminas, proteínas y minerales. Viene en una presentación de $113 \mathrm{~g}$, ideal para la capacidad gástrica del bebé, y está en un envase de plástico que garantiza la inocuidad del alimento. Asimismo, es un alimento complementario para el bebé a partir de los seis meses de edad, etapa en la que el principal alimento es la leche materna.

Tabla 1

Composición de la compota

\begin{tabular}{lc}
\hline Insumos & Gramos \\
\hline Pulpa de durazno & 105 \\
Harina de maca & 2 \\
Harina de quinua & 2 \\
Harina de kiwicha & 2 \\
Harina de cañihua & 2 \\
\hline Total & 113 \\
\hline
\end{tabular}

Elaboración propia

Tabla 2

Valor nutricional de la compota

\begin{tabular}{lccccc}
\hline Insumos & $\begin{array}{c}\text { Energía } \\
(\mathrm{kcal})\end{array}$ & $\begin{array}{c}\text { Energía } \\
(\mathrm{kJ})\end{array}$ & $\begin{array}{c}\text { Proteínas } \\
(\mathrm{g})\end{array}$ & $\begin{array}{c}\text { Grasa total } \\
(\mathrm{g})\end{array}$ & $\begin{array}{c}\text { Carbohidratos } \\
\text { totales }(\mathrm{g})\end{array}$ \\
\hline Pulpa de durazno & 67,2 & 281,4 & 0,63 & 0,105 & 17,955 \\
Harina de maca & 6,28 & 26,28 & 0,236 & 0,032 & 1,326 \\
Harina de quinua & 6,86 & 28,68 & 0,272 & 0,116 & 1,332 \\
Harina de kiwicha & 6,86 & 28,68 & 0,256 & 0,132 & 1,382 \\
Harina de cañihua & 6,88 & 28,78 & 0,286 & 0,1 & 1,256 \\
\hline Total & 94,08 & 393,82 & 1,68 & 0,485 & 23,251 \\
\hline
\end{tabular}

Fuente: INS, 2009 


\section{POTENCIALIDAD DEL RECURSO EN LA ZONA DE INFLUENCIA DEL PROYECTO}

El durazno se produce en las regiones que se indican en la tabla 3.

Tabla 3

Producción regional de durazno

\begin{tabular}{lc}
\hline & Producción regional de durazno en el 2015 \\
\hline Región & Producción (t) \\
\hline Lima & 35750 \\
Ancash, Ayacucho, Cusco, Apurímac, & 19250 \\
Moquegua y Tacna & 55000 \\
\hline Total & \\
\hline
\end{tabular}

Fuente: Producción de duraznos y néctares, 2015

Las otras materias primas se obtienen en las regiones señaladas en la tabla 4.

Tabla 4

Producción regional de materias primas

\begin{tabular}{|c|c|c|c|c|}
\hline \multirow[t]{2}{*}{ Región } & \multicolumn{4}{|c|}{ Producción 2015 (t) } \\
\hline & Cañihua & Kiwicha & Quinua & Maca \\
\hline Amazonas & & & 26 & \\
\hline Ancash & & 1003 & 1674 & \\
\hline Apurímac & & 1280 & 5785 & \\
\hline Arequipa & 7 & 1447 & 22356 & \\
\hline Ayacucho & & 116 & 14630 & \\
\hline Cajamarca & & & 572 & \\
\hline Cusco & 265 & 811 & 4337 & \\
\hline Huancavelica & & 49 & 1034 & 1711 \\
\hline Huánuco & & & 1428 & \\
\hline Ica & & & 958 & \\
\hline Junín & & & 8518 & 51447 \\
\hline La Libertad & & 130 & 3172 & \\
\hline Lambayeque & & 1 & 778 & \\
\hline Lima & & & 984 & 120 \\
\hline Moquegua & & & 106 & \\
\hline Pasco & & & 28 & 4609 \\
\hline Piura & & & 123 & \\
\hline Puno & 4462 & & 38221 & 82 \\
\hline Tacna & & & 891 & \\
\hline Total & 4734 & 4837 & 105621 & 57969 \\
\hline
\end{tabular}

Fuente: INEI, 2015 


\section{PROCESO DE PRODUCCIÓN}

El proceso inicia con la recepción de la materia prima e insumos. Llegan los duraznos en cajas, las harinas de maca, quinua, kiwicha y cañihua en sacos, los frascos y tapas en cajas, la solución desinfectante Tego en envases de plástico de 20 l, las planchas de cartón amarradas, las etiquetas en bobinas embolsadas y los camiones cisterna con soda cáustica líquida al 50 \% de concentración. Luego de la recepción se realiza el pesado de los duraznos y de las harinas de maca, quinua, kiwicha y cañihua en las básculas. Las harinas pasan por un control de calidad donde se evalúa si existe algún riesgo biológico (desarrollo de organismos patógenos y micotoxinas) mediante un análisis microbiológico, y de riesgo físico (incorporación de algún material que no sea harina) mediante un análisis físico organoléptico, en el cual el técnico de calidad mira, palpa y verifica el color de las harinas.

Luego de ser pesados, los duraznos son lavados con una solución de Tego al 0,1 \% en una máquina lavadora de frutas donde son empujados por la corriente de agua en combinación con un sistema compartimental de paletas de velocidad variable. Esta lavadora contiene una cinta transportadora modular montada sobre el fondo del tanque que permite un transporte controlado de los productos con flotabilidad negativa a través de la lavadora hasta el elevador de descarga. Para reforzar la acción de lavado convencional hay un sistema especial de agitación por aire que intensifica el resultado de lavado y limpieza. Después del lavado se realiza la selección, donde se eliminan todos los duraznos no aptos para el procesamiento (verdes, podridos o dañados) y los que no cumplen con el tamaño adecuado ( $\emptyset$ 56-61 mm y altura 54-59 mm, aproximadamente). Esto se realizará a través de una cinta transportadora, mediante inspección visual, siendo separados manualmente los seleccionados.

Los duraznos elegidos ingresan a la máquina descarozadora y son ubicados en las cavidades de la cadena portafrutos, la cual tiene un sistema de orientado automático (posiciona la zona de unión al pedúnculo hacia abajo y la sutura natural paralela hacia la cuchilla para que el corte la siga). Luego los duraznos son cortados mediante cuchillas planas y descarozados con cuchillas curvas. Finalmente, el conjunto de la fruta cae sobre una bandeja vibrante con perforaciones la cual separa los carozos de las mitades del durazno (6,2 \% del peso). Estas mitades son enviadas a la máquina orientadora, donde son colocadas con la copa hacia abajo mediante vibración; la velocidad de la máquina es de hasta 3000 mitades por minuto. Al salir son enviados a la peladora química.

Paralelamente a esto se realiza la dilución de la soda cáustica líquida que ingresó en camiones cisterna a una concentración del 50 \%, que es almacenada en tanques de polietileno de alta densidad, con muros de contención en caso de derrame. Para llevar a cabo la dilución de la soda cáustica se transporta mediante tuberías de acero al carbono a un tanque intermedio de polietileno de alta densidad el cual se llena de agua 
y posteriormente se permite su paso, concentrada al $50 \%$, hasta obtener una solución del 1,5 al $2 \%$. De este tanque intermedio, la soda cáustica diluida se transporta mediante tuberías a la peladora química.

En la peladora química los duraznos con la copa hacia abajo pasan por un sistema de ducha con hidróxido de sodio del 1,5 al $2 \%$, a una temperatura de 92 a $95^{\circ} \mathrm{C}$. Luego pasan por un envejecimiento por cámara de vapor vivo que concentra la soda cáustica sobre la piel del durazno, haciéndolo más efectivo, y finalmente por una ducha de agua que elimina la soda cáustica y la piel (12,4 \% del peso). Después de ser pelados, los duraznos en mitades pasan a un proceso de escaldado en el cual se desactivan las enzimas pécticas responsables del pardeamiento enzimático (que producen cambios desagradables en el color y sabor de las frutas) y para reblandecer su tejido para la posterior operación de despulpado, donde los duraznos en mitades pasan por la máquina despulpadora (la cual a su vez es tamizadora) y obtenemos una pasta fina (en caso de que los duraznos en mitades tengan residuos de cáscaras y carozos, estos se eliminan durante este proceso). Una vez obtenida, la pulpa de durazno está lista para el proceso de mezclado.

En el proceso de mezclado, la pulpa de durazno y las harinas de maca, quinua, kiwicha y cañihua son mezcladas de acuerdo a fórmula en la mezcladora de paletas por cinco minutos. Posteriormente, la mezcla es trasladada a la marmita de vapor eléctrica para el proceso de pasteurizado, en el cual se busca eliminar los microorganismos y patógenos que podrían alterar el producto, mediante tratamiento térmico a $90{ }^{\circ} \mathrm{C}$ por cinco minutos. En la parte izquierda de la marmita hay una bomba la que envía la pasta a un tanque de acero inoxidable para almacenar el producto y alimentar a la máquina llenadora-tapadora.

Antes de iniciar el proceso de llenado y tapado se deben esterilizar los envases de plástico y tapas en una máquina esterilizadora de tipo giratorio. El proceso de esterilizado se realiza en tres fases: en la primera se inyecta aire caliente a una temperatura de $80^{\circ} \mathrm{C}$ para un calentamiento previo de los envases y tapas; en la segunda se inyecta agua oxigenada nebulizada a una concentración del $30 \%$, y en la tercera fase se inyecta aire caliente a una temperatura de $80^{\circ} \mathrm{C}$, el cual permite eliminar posibles residuos de agua oxigenada. Luego de esto, los envases de plástico y tapas están listos para pasar a la máquina llenadora-tapadora.

En el llenado y tapado, la mezcla pasteurizada y los envases y tapas esterilizados ingresan a la máquina llenadora-tapadora al vacío la cual garantiza tener una compota inocua y de duración de seis meses en condiciones adecuadas de almacenamiento. Luego, las compotas pasan por una máquina etiquetadora automática con sensor, la cual detecta el envase y realiza el proceso de etiquetado. Finalmente las compotas son almacenadas en cajas de cartón mediante una máquina encajadora (en cada caja hay 200 compotas) para su venta. 
Tabla 5

Selección de la tecnología

\begin{tabular}{|c|c|c|}
\hline Operación & Tecnología & Descripción \\
\hline Pesado & Balanza portátil & $\begin{array}{l}\text { Para el pesado se seleccionó la balanza portátil ya que } \\
\text { permite movilizarla de acuerdo a los requerimientos del } \\
\text { proceso productivo. }\end{array}$ \\
\hline Lavado & Lavado por inmersión & $\begin{array}{l}\text { Para el lavado se seleccionó el lavado por inmersión } \\
\text { debido a que cumple con los requerimientos de limpieza } \\
\text { del durazno. }\end{array}$ \\
\hline Seleccionado & Faja transportadora & $\begin{array}{l}\text { Para el seleccionado se utilizará la faja transportadora ya } \\
\text { que se tendrá una sola línea de producción. }\end{array}$ \\
\hline Descarozado & $\begin{array}{l}\text { Máquina descarozadora } \\
\text { por cuchareo }\end{array}$ & $\begin{array}{l}\text { Para el descarozado se utilizará la máquina descarozadora } \\
\text { por cuchareo, la cual tiene un sistema de orientado } \\
\text { automático en las cavidades de la cadena portafrutos. }\end{array}$ \\
\hline Orientado & Máquina orientadora & $\begin{array}{l}\text { Para colocar los duraznos copa hacia abajo se utilizará la } \\
\text { máquina orientadora ya que realiza la función con más } \\
\text { rapidez y evita el error humano. }\end{array}$ \\
\hline Pelado químico & Método por aspersión & $\begin{array}{l}\text { Para el pelado químico se utilizará el método por aspersión } \\
\text { ya que tiene un uso más eficiente del agua. }\end{array}$ \\
\hline Escaldado & Por inmersión & $\begin{array}{l}\text { Para el escaldado se utilizará el escaldado por inmersión } \\
\text { ya que se adecúa más a la configuración de la línea de } \\
\text { producción. }\end{array}$ \\
\hline $\begin{array}{l}\text { Despulpado y } \\
\text { tamizado }\end{array}$ & Máquina despulpadora & $\begin{array}{l}\text { Para el despulpado y tamizado se utilizará una máquina } \\
\text { despulpadora a la cual se alimentarán duraznos en } \\
\text { mitades, lo que genera una mayor eficiencia en el proceso. }\end{array}$ \\
\hline Mezclado & Mezcladora de paletas & $\begin{array}{l}\text { Se utilizará una mezcladora de paletas ya que es la } \\
\text { adecuada para la mezcla de productos pastosos en la } \\
\text { industria de alimentos. }\end{array}$ \\
\hline Pasteurizado & Marmita a vapor eléctrica & $\begin{array}{l}\text { Se utilizará el pasteurizado mediante una marmita a vapor } \\
\text { eléctrica debido a que no depende de otra máquina para } \\
\text { trabajar. }\end{array}$ \\
\hline Esterilizado & $\begin{array}{l}\text { Esterilizadora de tipo } \\
\text { giratorio }\end{array}$ & $\begin{array}{l}\text { Se utilizará una esterilizadora de tipo giratorio la cual } \\
\text { realiza el proceso de esterilizado mediante aire caliente y } \\
\text { agua oxigenada. }\end{array}$ \\
\hline $\begin{array}{l}\text { Llenado y } \\
\text { tapado }\end{array}$ & Llenado y tapado al vacío & $\begin{array}{l}\text { Se utilizará una máquina llenadora tapadora al vacío debido } \\
\text { a que el producto no tiene preservantes y la ausencia de } \\
\text { oxígeno le permite una duración de seis meses. }\end{array}$ \\
\hline Etiquetado & Etiquetadora con sensor & $\begin{array}{l}\text { Se utilizará una máquina etiquetadora con sensor ya que } \\
\text { realiza el proceso más rápido y con menor porcentaje de } \\
\text { error. }\end{array}$ \\
\hline Encajado & Máquina encajadora & $\begin{array}{l}\text { Se utilizará una máquina encajadora ya que realiza el } \\
\text { proceso más rápido y con menor porcentaje de error. }\end{array}$ \\
\hline
\end{tabular}

Elaboración propia 


\section{BALANCE DE MATERIA}

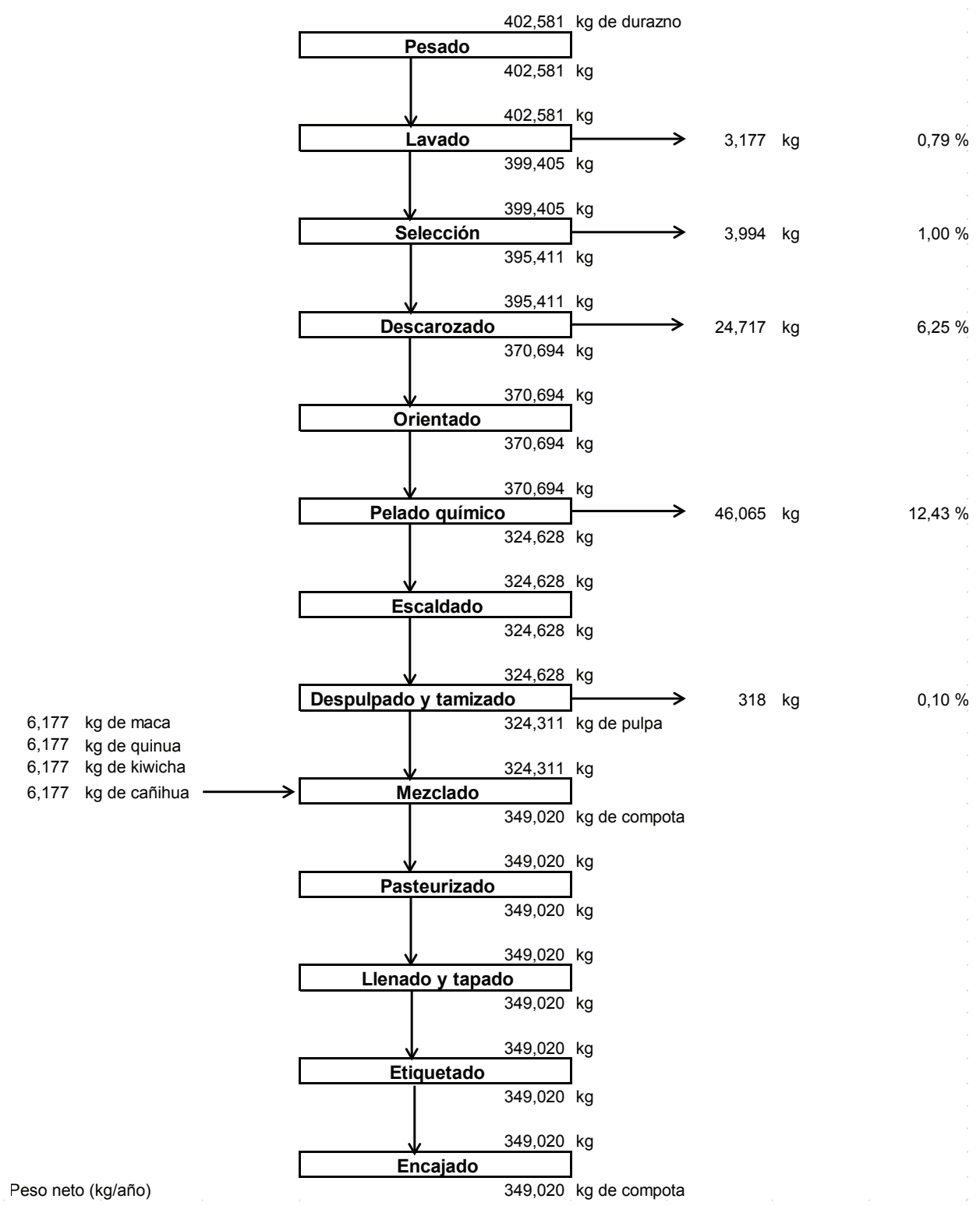

Figura 4. Balance de materia

Elaboración propia 
6. RESGUARDO DE CALIDAD E INOCUIDAD DEL PRODUCTO

\subsection{Calidad de la materia prima, de los insumos, del proceso y del producto}

\subsubsection{Calidad de la materia prima}

Para que el durazno (que representa el $93 \%$ del producto final) y la harina de maca, quinua, kiwicha y cañihua (que representan el $7 \%$ del producto final) se encuentren aptos para el proceso de producción deben cumplir con las características de la tabla 6.

Tabla 6

Características de las materias primas

\begin{tabular}{|c|c|}
\hline Materia prima & Requerimiento \\
\hline Durazno & $\begin{array}{l}\text { - Forma: Debe ser semiesférico, con un surco longitudinal bien } \\
\text { - } \text { marcado, de piel lisa o pubescente. } \\
\text { - } \text { Peso: } 127 \mathrm{amar} \text { a } 132 \mathrm{~g} . \\
\text { - Diámetro: } 56-61 \mathrm{~mm} \text {. } \\
\text { - } \text { Altura: } 54-59 \mathrm{~mm} \text {. } \\
\text { - Sabor: dulce. } \\
\text { - Olor: perfumado. }\end{array}$ \\
\hline Harina de maca & $\begin{array}{l}\text { - Debe estar libre de organismos patógenos y micotoxinas, y no } \\
\text { debe tener ningún material extraño que no sea harina. } \\
\text { - Color: beige claro. } \\
\text { - Humedad: máximo } 7 \% \text {. }\end{array}$ \\
\hline Harina de quinua & $\begin{array}{l}\text { - Debe estar libre de organismos patógenos y micotoxinas, y no } \\
\text { debe tener ningún material extraño que no sea harina. } \\
\text { - Color: beige claro. } \\
\text { - Humedad: máximo } 7 \% \text {. }\end{array}$ \\
\hline Harina de kiwicha & $\begin{array}{l}\text { - Debe estar libre de organismos patógenos y micotoxinas, y no } \\
\text { debe tener ningún material extraño que no sea harina. } \\
\text { - Color: beige claro. } \\
\text { - Humedad: máximo } 7 \% \text {. }\end{array}$ \\
\hline Harina de cañihua & $\begin{array}{l}\text { - Debe estar libre de organismos patógenos y micotoxinas, y no } \\
\text { debe tener ningún material extraño que no sea harina. } \\
\text { - Color: beige claro. } \\
\text { - Humedad: máximo } 7 \% \text {. }\end{array}$ \\
\hline
\end{tabular}

Elaboración propia

Dichas características deberán ser especificadas al proveedor para cumplir con la calidad de la compota. 


\subsubsection{Calidad de los insumos}

Al igual que la materia prima, los insumos a utilizar deben cumplir ciertos requerimientos de calidad (tabla 7).

Tabla 7

Características de los insumos

\begin{tabular}{ll}
\hline Insumo & \multicolumn{1}{c}{ Requerimiento } \\
\hline Envase & $\begin{array}{l}\text { Debe ser de PET y tener una superficie libre de ralladuras, abolladuras } \\
\text { o rajaduras. De un diámetro de } 55 \mathrm{~mm} \text { y altura de } 66 \mathrm{~mm} .\end{array}$ \\
Tapa & $\begin{array}{l}\text { Debe ser de PET. De un diámetro de } 55 \mathrm{~mm} \text { y altura } 10 \mathrm{~mm} . \\
\text { Etiqueta }\end{array}$ \\
\hline
\end{tabular}

Elaboración propia

Dichas características deberán ser especificadas a los proveedores de los insumos para cumplir con la calidad de la compota.

\subsubsection{Calidad en el proceso}

Se realizará un control de calidad en las siguientes etapas:

Al recibir las harinas de maca, quinua, kiwicha y cañihua, se seleccionará una muestra de cada una y se le realizará un análisis microbiológico para descartar el desarrollo de organismos patógenos y micotoxinas; asimismo, se le realizará un análisis físico organoléptico en el cual el técnico de calidad mira, palpa y verifica el color de las harinas para descartar que incorporen algún material extraño.

Después de esterilizar los frascos y tapas, se seleccionará una muestra aleatoria de frascos y tapas y se le realizará una prueba de conteo de colonias. En esta prueba se pasará un hisopo en el frasco y un hisopo en la tapa y se colocarán las muestras en un medio de cultivo. Luego se realizará una prueba de crecimiento de bacterias a temperatura ambiente, temperatura refrigerada y temperaturas mayores para saber si hay bacterias. El límite máximo permisible es de $10^{3}$ hasta $10^{6}$ bacterias.

Luego del pasteurizado de la mezcla, se tomará una muestra de la mezcla y se le realizará una prueba de conteo de colonias. En esta prueba se colocará la muestra en un medio de cultivo. Luego se realizará una prueba de crecimiento de bacterias a temperatura ambiente, temperatura refrigerada y temperaturas mayores para saber si hay bacterias. El límite máximo permisible es de $10^{3}$ hasta $10^{6}$ bacterias para resguardar la calidad del producto. 
Además, para garantizar la salubridad del producto se les entregarán a los operarios que intervengan en el proceso de producción los siguientes elementos de protección: guantes, mascarillas, traje de cuerpo que incluye la protección a la cabeza y cubrezapatos.

\subsubsection{Calidad en el producto terminado}

Según la norma Codex STAN 73-1981, el producto final debe cumplir con lo siguiente:

- El producto se envasará en recipientes que preserven las cualidades higiénicas o de otra índole del alimento. El contenido del envase no será inferior al $80 \%$ del volumen del envase cuando pese menos de $150 \mathrm{~g}$.

- En la etiqueta, el nombre del alimento llevará el del ingrediente o ingredientes más importantes o característicos e irá seguido de las indicaciones necesarias sobre su consistencia o sobre el uso a que se destina. En la etiqueta figurará la lista completa de los ingredientes, por orden decreciente de proporciones, salvo cuando se hayan añadido vitaminas o minerales, que se indicarán como grupos de vitaminas o de minerales, respectivamente, sin que dentro de tales grupos sea necesaria su enumeración por orden decreciente de proporciones.

- La declaración de información sobre nutrición deberá contener la cantidad de energía expresada en calorías (kcal) o kilojulios (kJ), y el número en g de proteínas, carbohidratos y grasa por cada $100 \mathrm{~g}$ de alimento vendido, así como por cada cantidad determinada de alimento cuyo consumo se sugiere.

- Se indicará la fecha de duración mínima (precedida de la expresión "Consumir preferentemente antes del") mediante el día, mes y el año, en orden numérico no cifrado, con la excepción de que, para los productos que tengan una duración superior a tres meses, bastará la indicación del mes y del año. El mes podrá indicarse por letras en aquellos países en los que esta indicación no induzca a confusión al consumidor. Cuando se trate de productos en que solo se requiera la declaración del mes y del año, y la duración del producto alcance hasta el final de un determinado año, podrá emplearse como alternativa la expresión "fin de (indicar el año)".

- Además de la fecha se indicarán condiciones especiales para la conservación del alimento si de su cumplimiento depende la validez de la fecha. Siempre que sea factible, las instrucciones para la conservación deberán figurar lo más cerca posible de la marca que indica la fecha. En la etiqueta o en el folleto que acompaña al producto se darán instrucciones sobre su preparación y uso, así como sobre su almacenamiento y conservación después de abrirse el envase.

- El producto no es substitutivo de la leche materna y no deberá presentarse así. 
Adicionalmente, cuando la compota está en el almacén de producto terminado se seleccionará una muestra de forma aleatoria, se verificará que el envase esté sellado; luego se procederá a abrirlo, se tomará una muestra de la compota y se le realizará una prueba de conteo de colonias. En esta prueba se colocará la muestra en un medio de cultivo. Luego se realizará una prueba de crecimiento de bacterias a temperatura ambiente, temperatura refrigerada y temperaturas mayores para saber si hay bacterias. El límite máximo permisible es de $10^{3}$ hasta $10^{6}$ bacterias para resguardar la calidad del producto. Asimismo, se comparará el producto contra una muestra estándar y se verificará que tenga el mismo color, olor, sabor, textura y consistencia.

\subsection{Medidas de resguardo de la calidad en la producción}

Para el resguardo de la calidad en la producción se utilizará el sistema HACCP, que permite identificar peligros específicos y medidas para su control con el fin de garantizar la inocuidad de los alimentos. Se procederá a realizar el análisis de riesgos (tabla 8).

Tabla 8

Análisis de riesgos

\begin{tabular}{|c|c|c|c|c|}
\hline Etapa & Peligro & $\begin{array}{c}\text { ¿Peligro } \\
\text { significativo? }\end{array}$ & $\begin{array}{l}\text { Justificación } \\
\text { de la decisión }\end{array}$ & $\begin{array}{l}\text { ¿Qué medidas } \\
\text { preventivas pueden } \\
\text { ser aplicadas? }\end{array}$ \\
\hline $\begin{array}{l}\text { Recepción de las } \\
\text { cajas de duraznos }\end{array}$ & $\begin{array}{l}\text { - Deterioro de } \\
\text { las condiciones } \\
\text { físicas, químicas y } \\
\text { microbiológicas del } \\
\text { durazno }\end{array}$ & Sí & $\begin{array}{l}\text { - Mala } \\
\text { manipulación de } \\
\text { las cajas durante } \\
\text { la entrega que } \\
\text { ocasiona golpes } \\
\text { y aceleración } \\
\text { del proceso de } \\
\text { putrefacción de } \\
\text { los duraznos }\end{array}$ & $\begin{array}{l}\text { Controlar y evaluar } \\
\text { constantemente } \\
\text { los envíos de } \\
\text { los proveedores. } \\
\text { Mejorar los } \\
\text { procedimientos } \\
\text { de descarga y } \\
\text { recepción }\end{array}$ \\
\hline $\begin{array}{l}\text { Recepción de las } \\
\text { harinas de maca, } \\
\text { quinua, kiwicha y } \\
\text { cañihua }\end{array}$ & $\begin{array}{l}\text { - Contaminación } \\
\text { física por materiales } \\
\text { extraños } \\
\text { - Aparición de } \\
\text { insectos } \\
\text { - Contaminación } \\
\text { química y } \\
\text { microbiológica }\end{array}$ & Sí & $\begin{array}{l}\text { - Mal cosido de } \\
\text { los sacos que } \\
\text { contienen las } \\
\text { harinas } \\
\text { - Inadecuadas } \\
\text { condiciones de } \\
\text { transporte } \\
\text { - Manejo de } \\
\text { los sacos en } \\
\text { condiciones } \\
\text { higiénicas no } \\
\text { adecuadas }\end{array}$ & $\begin{array}{l}\text { Evaluación } \\
\text { constante de los } \\
\text { proveedores. Los } \\
\text { envíos deben } \\
\text { realizarse en } \\
\text { sacos esterilizados } \\
\text { Controles } \\
\text { exhaustivos. } \\
\text { Verificar la } \\
\text { integridad de los } \\
\text { lotes de pedido }\end{array}$ \\
\hline
\end{tabular}


(continuación)

\begin{tabular}{|c|c|c|c|c|}
\hline $\begin{array}{l}\text { Recepción del } \\
\text { hidróxido de sodio }\end{array}$ & $\begin{array}{l}\text { - Quemaduras } \\
\text { nasales, en la boca, } \\
\text { esófago, estómago y } \\
\text { en la piel }\end{array}$ & Sí & $\begin{array}{l}\text { - Mala manipulación } \\
\text { en la descarga }\end{array}$ & $\begin{array}{l}\text { Capacitación a los } \\
\text { operarios sobre } \\
\text { la descarga del } \\
\text { hidróxido de sodio }\end{array}$ \\
\hline $\begin{array}{l}\text { Recepción de la } \\
\text { gasolina de } 98 \\
\text { octanos }\end{array}$ & $\begin{array}{l}\text { - Explosión, los } \\
\text { vapores generan } \\
\text { náuseas, dolor de } \\
\text { cabeza, alteraciones } \\
\text { al sistema nervioso } \\
\text { central; su } \\
\text { ingestión provoca } \\
\text { diarrea, mareos } \\
\text { e intoxicación } \\
\text { y su contacto } \\
\text { con la piel y ojos } \\
\text { produce irritación, } \\
\text { conjuntivitis y } \\
\text { quemaduras }\end{array}$ & Sí & $\begin{array}{l}\text { - Mala manipulación } \\
\text { en la descarga }\end{array}$ & $\begin{array}{l}\text { Capacitación a los } \\
\text { operarios sobre } \\
\text { la descarga del } \\
\text { combustible y } \\
\text { conectar los barriles } \\
\text { de combustible a } \\
\text { tierra }\end{array}$ \\
\hline $\begin{array}{l}\text { Recepción de la } \\
\text { solución de Tego }\end{array}$ & - Envases rajados & Sí & $\begin{array}{l}\text { - El líquido } \\
\text { desinfectante } \\
\text { podría entrar en } \\
\text { contacto con algún } \\
\text { otro insumo }\end{array}$ & $\begin{array}{l}\text { No recepción } \\
\text { de envases con } \\
\text { solución de Tego en } \\
\text { malas condiciones }\end{array}$ \\
\hline $\begin{array}{l}\text { Almacenamiento } \\
\text { de los duraznos }\end{array}$ & $\begin{array}{l}\text { - Deterioro de } \\
\text { las condiciones } \\
\text { físicas, químicas y } \\
\text { microbiológicas del } \\
\text { durazno }\end{array}$ & Sí & $\begin{array}{l}\text { - Altera la calidad } \\
\text { del producto final } \\
\text { - Es perjudicial para } \\
\text { la salud de los } \\
\text { infantes }\end{array}$ & $\begin{array}{l}\text { Evaluación de } \\
\text { las condiciones } \\
\text { ambientales } \\
\text { del almacén de } \\
\text { materias primas a } \\
\text { fin de controlar la } \\
\text { vida útil del durazno }\end{array}$ \\
\hline $\begin{array}{l}\text { Almacenamiento } \\
\text { de las harinas } \\
\text { de maca, quinua, } \\
\text { kiwicha y cañihua }\end{array}$ & $\begin{array}{l}\text { - Deterioro del } \\
\text { producto y } \\
\text { disminución de su } \\
\text { vida útil } \\
\text { - Enranciamiento de } \\
\text { las harinas }\end{array}$ & Sí & $\begin{array}{l}\text { - Rotura de los } \\
\text { sacos } \\
\text { - Posible presencia } \\
\text { de roedores } \\
\text { e insectos } \\
\text { Inadecuadas } \\
\text { condiciones } \\
\text { ambientales en el } \\
\text { almacén }\end{array}$ & $\begin{array}{l}\text { Realizar controles } \\
\text { de temperatura } \\
\text { en el almacén de } \\
\text { materia prima } \\
\text { Realizar un } \\
\text { programa de } \\
\text { limpieza y } \\
\text { fumigación en los } \\
\text { tres almacenes }\end{array}$ \\
\hline Dilución & - Explosión & Sí & $\begin{array}{l}\text { - Si no se realiza } \\
\text { el procedimiento } \\
\text { establecido para } \\
\text { la dilución del } \\
\text { hidróxido de sodio } \\
\text { concentrado } \\
\text { hay riesgo de } \\
\text { explosión }\end{array}$ & $\begin{array}{l}\text { Capacitación a los } \\
\text { operarios sobre } \\
\text { el procedimiento } \\
\text { de dilución del } \\
\text { hidróxido de sodio } \\
\text { concentrado }\end{array}$ \\
\hline
\end{tabular}


(continuación)

\begin{tabular}{|c|c|c|c|c|}
\hline Pasteurizado & $\begin{array}{l}\text { - Los } \\
\text { microorganismos } \\
\text { y organismos } \\
\text { patógenos } \\
\text { sobreviven al } \\
\text { pasteurizado. }\end{array}$ & Sí & $\begin{array}{l}\text { - Del pasteurizado } \\
\text { depende el tiempo } \\
\text { de duración de } \\
\text { la compota y su } \\
\text { calidad. }\end{array}$ & $\begin{array}{l}\text { Verificar que se } \\
\text { hace el pasteurizado } \\
\text { de acuerdo a } \\
\text { los parámetros } \\
\text { establecidos. }\end{array}$ \\
\hline Esterilizado & $\begin{array}{l}\text { - Presencia de } \\
\text { microorganismos } \\
\text { en los envases y } \\
\text { tapas después del } \\
\text { esterilizado. }\end{array}$ & Sí & $\begin{array}{l}\text { - Es indispensable } \\
\text { que los envases } \\
\text { y tapas estén } \\
\text { esterilizados } \\
\text { para garantizar } \\
\text { la inocuidad de la } \\
\text { compota. }\end{array}$ & $\begin{array}{l}\text { Verificar que se } \\
\text { realiza el proceso } \\
\text { de esterilizado } \\
\text { de acuerdo a } \\
\text { los parámetros } \\
\text { establecidos. }\end{array}$ \\
\hline
\end{tabular}

Elaboración propia

A partir de la tabla 8 es posible concluir que los puntos críticos de control son la recepción del hidróxido de sodio, la recepción de la gasolina de 98 octanos, dilución, pasteurizado y esterilizado.

Luego se procederá a realizar el análisis de los puntos críticos de control identificados en la tabla 9, los cuales son esenciales para prevenir o eliminar un peligro relacionado con la inocuidad de los alimentos o para reducirlo a un nivel aceptable.

\section{ESTUDIO DE IMPACTO AMBIENTAL}

Se procederá a realizar el análisis de las operaciones del proceso de producción e identificación de los posibles impactos ambientales que pudieran generar (tabla 10).

\section{ESTUDIO DE SEGURIDAD Y SALUD OCUPACIONAL}

Para la planificación del sistema de gestión de la seguridad se utilizará el método IPER, que permite priorizar los riesgos en función del nivel crítico establecido, y las acciones preventivas se desarrollarán en base a los riesgos priorizados (tabla 11). 


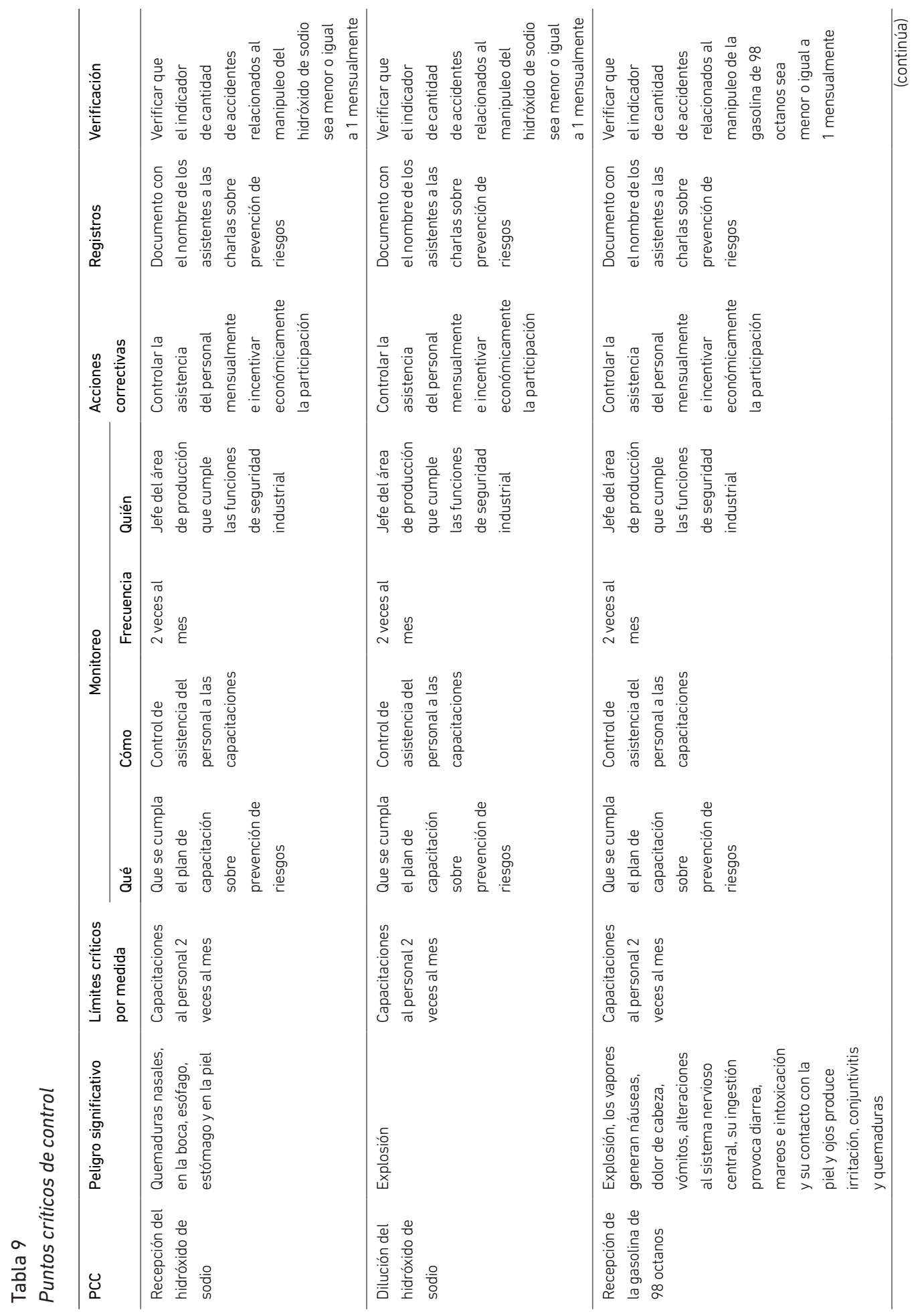




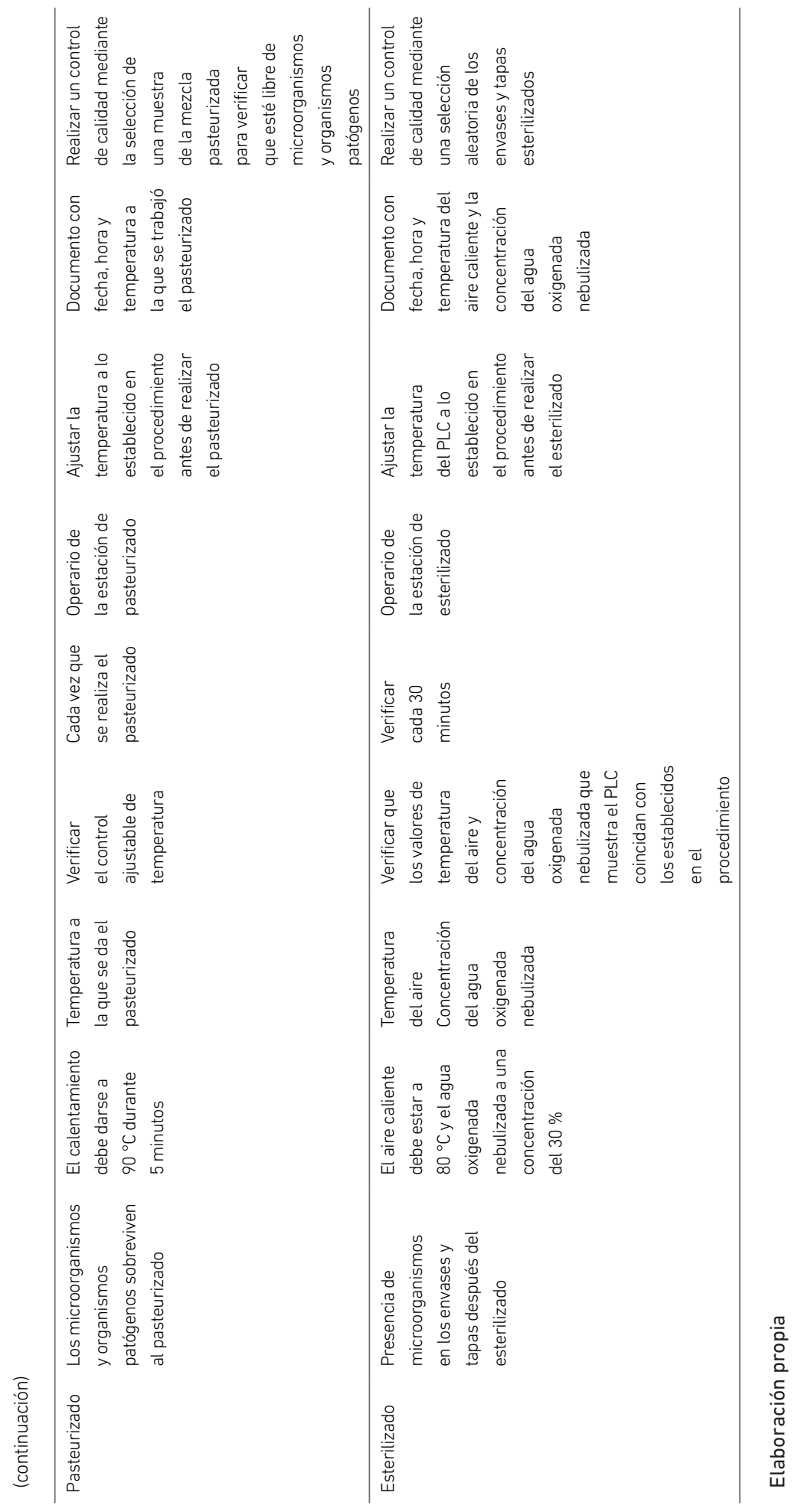


Tabla 10

Impactos ambientales

\begin{tabular}{|c|c|c|c|}
\hline Actividad & Salidas & Impacto ambiental & Medida correctiva \\
\hline $\begin{array}{l}\text { Recepción de } \\
\text { materias primas, } \\
\text { insumos y } \\
\text { combustible }\end{array}$ & $\begin{array}{l}\text { Emisión de } \\
\text { dióxido de } \\
\text { carbono por } \\
\text { parte de los } \\
\text { camiones }\end{array}$ & $\begin{array}{l}\text { Contaminación del } \\
\text { aire por aumento } \\
\text { de gases de efecto } \\
\text { invernadero }\end{array}$ & $\begin{array}{l}\text { Solicitar a los proveedores que } \\
\text { realicen mantenimientos periódicos a } \\
\text { los motores de los camiones para que } \\
\text { tengan una combustión completa }\end{array}$ \\
\hline $\begin{array}{l}\text { Almacenamiento de } \\
\text { materias primas e } \\
\text { insumos }\end{array}$ & $\begin{array}{l}\text { Emisión de } \\
\text { dióxido de } \\
\text { carbono por } \\
\text { parte de los } \\
\text { montacargas }\end{array}$ & $\begin{array}{l}\text { Contaminación del } \\
\text { aire por aumento } \\
\text { de gases de efecto } \\
\text { invernadero }\end{array}$ & $\begin{array}{l}\text { Mantenimiento mensual al motor del } \\
\text { montacargas para que realice una } \\
\text { combustión completa }\end{array}$ \\
\hline Pesado & Ninguno & Ninguno & Ninguno \\
\hline Control de calidad & Ninguno & Ninguno & Ninguno \\
\hline $\begin{array}{l}\text { Lavado de los } \\
\text { duraznos }\end{array}$ & $\begin{array}{l}\text { Agua con } \\
\text { solución de Tego } \\
\text { y restos de } \\
\text { tierra } \\
\text { Envases de la } \\
\text { solución de Tego }\end{array}$ & $\begin{array}{l}\text { Contaminación } \\
\text { del agua } \\
\text { Contaminación } \\
\text { por generación de } \\
\text { residuos sólidos }\end{array}$ & $\begin{array}{l}\text { Tratamiento de efluentes en la planta } \\
\text { de tratamiento de aguas residuales de } \\
\text { Ventanilla } \\
\text { Vender los envases de plástico a } \\
\text { empresas recicladoras de plástico }\end{array}$ \\
\hline Seleccionado & $\begin{array}{l}\text { Duraznos verdes, } \\
\text { podridos o } \\
\text { dañados }\end{array}$ & $\begin{array}{l}\text { Contaminación } \\
\text { por generación de } \\
\text { residuos sólidos }\end{array}$ & $\begin{array}{l}\text { Vender los duraznos verdes, podridos } \\
\text { o dañados a empresas fabricadoras } \\
\text { de compost }\end{array}$ \\
\hline Descarozado & $\begin{array}{l}\text { Restos de } \\
\text { carozo. }\end{array}$ & $\begin{array}{l}\text { Contaminación } \\
\text { por generación de } \\
\text { residuos sólidos }\end{array}$ & $\begin{array}{l}\text { Vender los restos de carozo a } \\
\text { empresas fabricadoras de compost }\end{array}$ \\
\hline Orientado & Ninguno & Ninguno & Ninguno \\
\hline Dilución & Ninguno & Ninguno & Ninguno \\
\hline Pelado químico & $\begin{array}{l}\text { Agua con } \\
\text { hidróxido de } \\
\text { sodio y restos } \\
\text { de cáscara de } \\
\text { durazno }\end{array}$ & $\begin{array}{l}\text { Contaminación del } \\
\text { agua }\end{array}$ & $\begin{array}{l}\text { Tratamiento de efluentes en la planta } \\
\text { de tratamiento de aguas residuales de } \\
\text { Ventanilla }\end{array}$ \\
\hline Escaldado & $\begin{array}{l}\text { Agua con restos } \\
\text { de durazno }\end{array}$ & $\begin{array}{l}\text { Contaminación del } \\
\text { agua }\end{array}$ & $\begin{array}{l}\text { Tratamiento de efluentes en la planta } \\
\text { de tratamiento de aguas residuales de } \\
\text { Ventanilla }\end{array}$ \\
\hline $\begin{array}{l}\text { Despulpado y } \\
\text { tamizado }\end{array}$ & $\begin{array}{l}\text { Restos de carozo } \\
\text { y cáscaras de } \\
\text { durazno }\end{array}$ & $\begin{array}{l}\text { Contaminación } \\
\text { por generación de } \\
\text { residuos sólidos }\end{array}$ & $\begin{array}{l}\text { Vender los restos de carozo y cáscaras } \\
\text { de durazno a empresas fabricadoras } \\
\text { de compost }\end{array}$ \\
\hline Mezclado & $\begin{array}{l}\text { Sacos que } \\
\text { contenían las } \\
\text { harinas }\end{array}$ & $\begin{array}{l}\text { Contaminación } \\
\text { por generación de } \\
\text { residuos sólidos }\end{array}$ & $\begin{array}{l}\text { Devolver los sacos al proveedor para } \\
\text { su reutilización }\end{array}$ \\
\hline Pasteurizado & Ninguno & Ninguno & Ninguno \\
\hline
\end{tabular}


(continuación)

\begin{tabular}{llll}
\hline Esterilizado & $\begin{array}{l}\text { Vapor de agua } \\
\text { oxigenada }\end{array}$ & $\begin{array}{l}\text { Contaminación del } \\
\text { aire }\end{array}$ & $\begin{array}{l}\text { Ninguno pues la contaminación es } \\
\text { mínima }\end{array}$ \\
\hline Llenado y tapado & Ninguno & Ninguno & Ninguno \\
\hline Etiquetado & $\begin{array}{l}\text { Bolsas de } \\
\text { plástico que } \\
\text { contenían las } \\
\text { bobinas de } \\
\text { etiquetas }\end{array}$ & $\begin{array}{l}\text { Contaminación } \\
\text { por generación de } \\
\text { residuos sólidos }\end{array}$ & $\begin{array}{l}\text { Vender las bolsas de plástico a } \\
\text { empresas recicladoras de plástico }\end{array}$ \\
\hline Rafia & Contaminación & Vender la rafia a empresas \\
& & $\begin{array}{l}\text { por generación de } \\
\text { residuos sólidos }\end{array}$ & recicladoras de plástico \\
\hline $\begin{array}{l}\text { Encajado } \\
\text { producto terminado }\end{array}$ & $\begin{array}{l}\text { Emisión de } \\
\text { dióxido de } \\
\text { carbono por } \\
\text { parte de los } \\
\text { montacargas }\end{array}$ & $\begin{array}{l}\text { Contaminación del } \\
\text { aire por aumento } \\
\text { de gases de efecto } \\
\text { invernadero }\end{array}$ & $\begin{array}{l}\text { Mantenimiento mensual al motor del } \\
\text { montacargas para que realice una } \\
\text { combustión completa }\end{array}$ \\
\hline
\end{tabular}

\section{Elaboración propia}


Estudio para la elaboración de compotas para bebés a partir de durazno

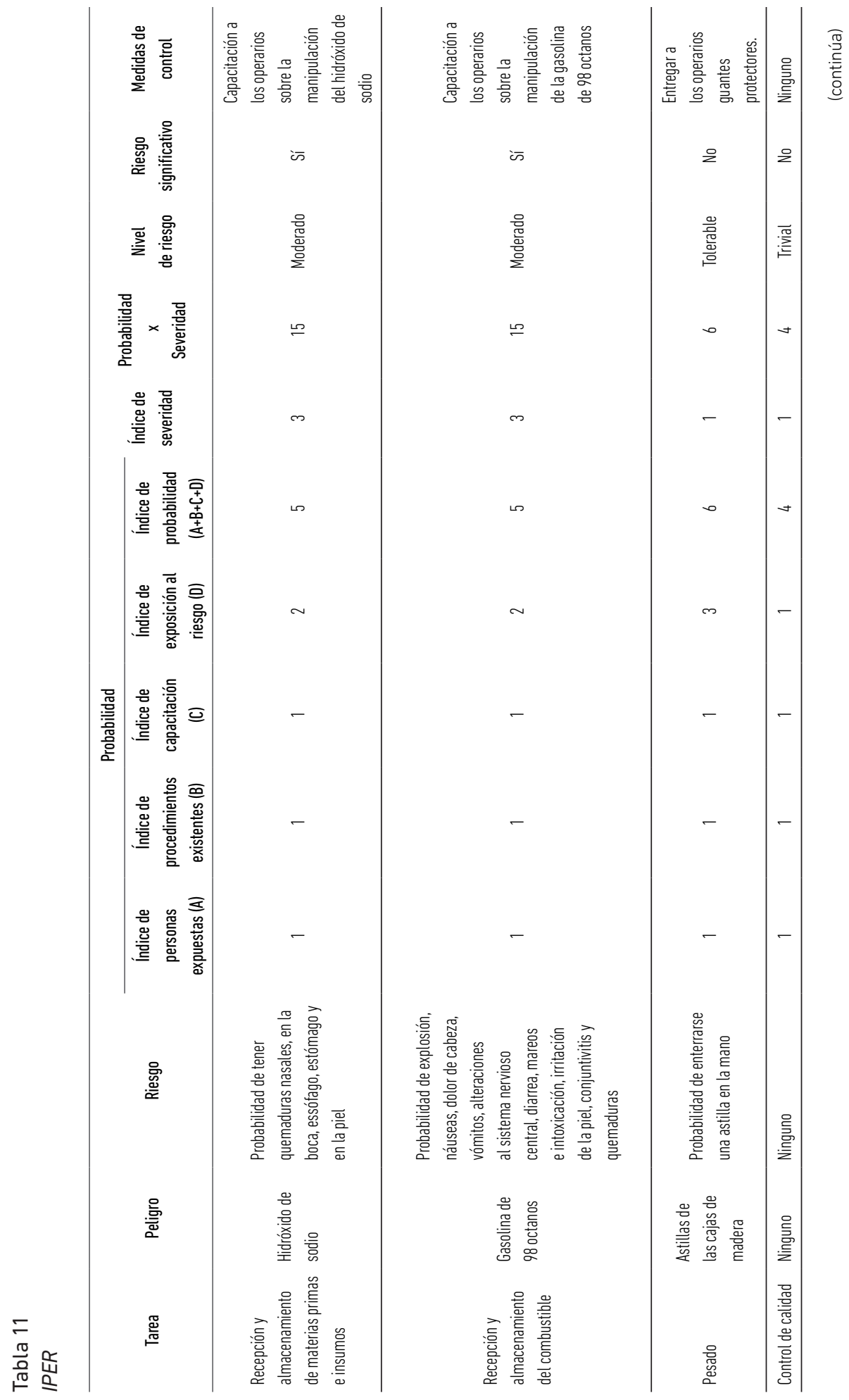




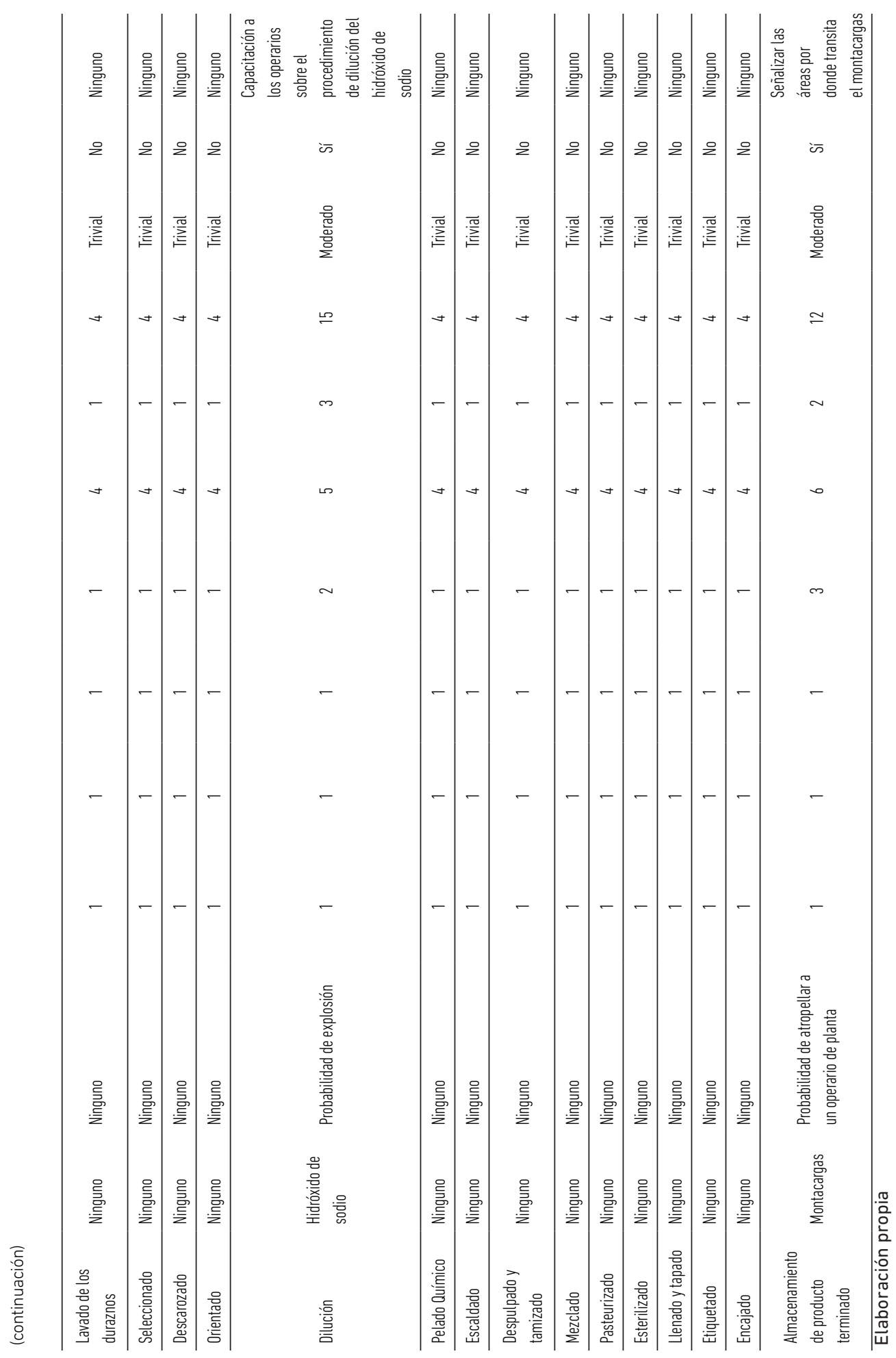


Tabla 12

Criterios de evaluación IPER

\begin{tabular}{|c|c|c|c|c|c|}
\hline \multirow[b]{2}{*}{ Índice } & \multicolumn{4}{|c|}{ Probabilidad } & \multirow{2}{*}{$\begin{array}{c}\text { Severidad } \\
\text { (consecuencia) }\end{array}$} \\
\hline & $\begin{array}{l}\text { Personas } \\
\text { expuestas }\end{array}$ & $\begin{array}{l}\text { Procedimientos } \\
\text { existentes }\end{array}$ & Capacitación & $\begin{array}{l}\text { Exposición } \\
\text { al riesgo }\end{array}$ & \\
\hline 1 & 1 a 3 & $\begin{array}{l}\text { Existen, son } \\
\text { satisfactorios y } \\
\text { suficientes }\end{array}$ & $\begin{array}{l}\text { Personal entrenado, } \\
\text { conoce el peligro y lo } \\
\text { previene }\end{array}$ & $\begin{array}{l}\text { Al menos una } \\
\text { vez al año, } \\
\text { esporádicamente }\end{array}$ & $\begin{array}{c}\text { Lesión sin } \\
\text { incapacidad. } \\
\text { INCOMODIDAD }\end{array}$ \\
\hline 2 & 4 a 12 & $\begin{array}{l}\text { Existen parcialmente } \\
\text { y no son satisfactorios } \\
\text { o suficientes }\end{array}$ & $\begin{array}{l}\text { Personal parcialmente } \\
\text { entrenado, conoce el } \\
\text { peligro pero no toma } \\
\text { acciones de control }\end{array}$ & $\begin{array}{l}\text { Al menos una } \\
\text { vez al mes, } \\
\text { eventualmente }\end{array}$ & $\begin{array}{l}\text { Lesión con } \\
\text { incapacidad } \\
\text { DAÑO A SALUD } \\
\text { REVERSIBLE }\end{array}$ \\
\hline 3 & 12 a más & No existen & $\begin{array}{l}\text { Personal no entrenado, } \\
\text { no conoce el peligro, } \\
\text { no toma acciones de } \\
\text { control }\end{array}$ & $\begin{array}{l}\text { Al menos una vez } \\
\text { al día, permanente }\end{array}$ & $\begin{array}{c}\text { Lesión con } \\
\text { incapacidad } \\
\text { DAÑO A SALUD } \\
\text { IRREVERSIBLE }\end{array}$ \\
\hline
\end{tabular}

Elaboración propia

Tabla 13

Nivel de riesgo

\begin{tabular}{|c|c|}
\hline Nivel de riesgo & Postura \\
\hline $\begin{array}{l}\text { Trivial } \\
4\end{array}$ & - $\quad$ No requiere acción específica \\
\hline $\begin{array}{l}\text { Tolerable } \\
5-8\end{array}$ & $\begin{array}{l}\text { - } \quad \text { Mantener eficacia de las acciones preventivas } \\
\text { - } \quad \text { Buscar alternativas más económicas } \\
\text { - } \quad \text { Comprobar e inspeccionar periódicamente para mantener el nivel }\end{array}$ \\
\hline $\begin{array}{l}\text { Moderado } \\
9-16\end{array}$ & $\begin{array}{l}\text { - Aplicar acciones para reducir el riesgo en un plazo determinado } \\
\text { - Si el riesgo está asociado a consecuencias extremadamente dañinas } \\
\text { (mortal o grave), volver a evaluar para mejorar resultados }\end{array}$ \\
\hline $\begin{array}{c}\text { Importante } \\
17-24\end{array}$ & $\begin{array}{l}\text { - } \quad \text { No empezar el trabajo hasta reducir el riesgo } \\
\text { - } \quad \text { Es posible que requiera importantes recursos para control del riesgo } \\
\text { - Si el riesgo está asociado a un trabajo que está realizándose, solucionar } \\
\text { en corto plazo }\end{array}$ \\
\hline $\begin{array}{c}\text { Intolerable } \\
25-36\end{array}$ & $\begin{array}{l}\text { - No empezar ni continuar el proceso hasta no reducir el riesgo } \\
\text { - Si no es posible reducir el riesgo, prohibir el trabajo (incluso con recursos } \\
\text { limitados) }\end{array}$ \\
\hline
\end{tabular}

Elaboración propia 


\section{CONCLUSIÓN}

El proyecto es viable técnicamente debido a que es posible producir la compota; se dispone de la tecnología y de las materias primas. Asimismo, se garantizan las medidas de seguridad y salud ocupacional y se controlan los posibles impactos ambientales. El cuello de botella es la estación de etiquetado, que tiene una tasa de producción de 339 $\mathrm{kg} / \mathrm{hora}$, la cual determina la velocidad del proceso. Los riesgos más significativos del proceso son los relacionados a las tareas de recepción y almacenamiento de materias primas e insumos, recepción y almacenamiento de combustible, dilución del hidróxido de sodio y almacenamiento del producto terminado.

\section{REFERENCIAS}

Concha Pacheco, F. M. (1989). La desnutrición y sus efectos en el desarrollo del niño. Lima: San Marcos.

Instituto Nacional de Estadística e Informática (INEI). (2015). Series nacionales. Recuperado de https://www.inei.gob.pe/sistemas-consulta/

Instituto Nacional de Salud (INS). (2009). Tablas peruanas de composición de alimentos. Lima: Ministerio de Salud.

Instituto Nacional de Salud (INS) (2014). Estado nutricional en niños y gestantes de los establecimientos de salud del Ministerio de Salud. Lima: Ministerio de Salud.

Mendoza Flores, A. (1994). La niñez en el Perú: Desnutrición y déficit intelectual y físico: Cómo evitar el deterioro a las futuras generaciones. Lima: DESA.

Producción de duraznos y néctares (2015). Euromonitor. Recuperado de http://www. euromonitor.com/

United Nations International Children's Emergency Fund (UNICEF) (2011). Consecuencias de la desnutrición infantil. Madrid.

\section{BIBLIOGRAFÍA}

Aldana Minaya, H. y Rivas Romero, R. A. (2016). Estudio de pre-factibilidad para la instalación de una planta productora de compotas para bebés a partir de durazno (Prunus persica) enriquecido con maca (Lepidium meyenii Walpers), quinua (Chenopodium quinoa Willd), kiwicha (Amaranthus caudatus Linnaeus) y cañihua (Chenopodium pallidicaule). (Tesis para optar el título de Ingeniero Industrial). Universidad de Lima. 
Arroyo Trujillano, N. C. (2002). Estudio de prefactibilidad para la instalación de una planta procesadora de alimentos para bebés a base de quinua, kiwicha, cañihua, manzana, plátano y leche. (Tesis para optar el título de Ingeniero Industrial). Universidad de Lima.

Carrillo Tan, S. R. (1992). Estudio de factibilidad para instalar una planta de extracción de pulpa de durazno (Prunus persica) en la provincia de Huaral. (Tesis para optar el título de Ingeniero Industrial). Universidad de Lima.

Castro, J. (2007). Con su reputación de vigorizante mágico la maca se pasea por el mundo. Perú empresarial 12, p. 10.

Chávez Álvarez, J. (2006). Plantas medicinales. Caser: Riesgos de mercados. Lima: Maximize.

Díaz, B., Jarufe, B. y Noriega, M. T. (2007). Disposición de planta. Lima: Universidad de Lima, Fondo Editorial.

Dobkin, L. (2008). Renace la quinua. Américas 60(5), pp. 28-37.

Escobedo, A. P. (2011). Estudio preliminar para la instalación de una planta productora de compotas para bebés de lúcuma enriquecida con kiwicha. (Seminario de investigación de Ingeniería Industrial). Lima: Universidad de Lima.

Konz, S. (1991). Diseño de instalaciones industriales. México: Noriega Limusa.

La quinua: lágrimas del sol (2008). Sommelier, vinos y más 34, pp. 46-48.

Meyhuay M. (1999). El alto valor de la quinua. Multimodal 7, p. 34.

Mujica, A. E. (1999). Resúmenes de investigaciones en quinua (Chenopodium, quinoa Willd) de la Universidad Nacional del Altiplano. Puno: Universidad Nacional del Altiplano.

Organización de las Naciones Unidas para la Alimentación y la Agricultura (FAO). (1981). Norma para alimentos envasados para lactantes y niños CODEX STAN 73-1981. Recuperado de http://www.fao.org/fao-who-codexalimentarius/sh-proxy/en/? lnk=1\&url=https\%253A\%252F\%252Fworkspace.fao.org\%252Fsites\%252Fcodex \%252FStandards\%252FCODEX\%2BSTAN\%2B73-1981\%252FCXS_073s.pdf

Pollitt Burga, E. (2002). Consecuencias de la desnutrición en el escolar peruano. Lima: Pontificia Universidad Católica del Perú.

Pollitt Burga, E. (2007). Desnutrición, pobreza e inteligencia. Lima: Universidad Ricardo Palma.

Reaño M., V. (2011). Sano deleite: Las grandes marcas apuestan por más granos andinos. Semana económica 1279(26), p. 30. 
Sapag Chain, N. (2014). Preparación y evaluación de proyectos. México: McGraw-Hill.

Scott, G. (1987). La kiwicha: Un enfoque socioeconómico. Proceso económico 64, p. 25.

Sumar Kalinowsi, L. (1986). Nuevas alternativas alimentarias para el Perú. Agro Enfoque 4, p. 12.

Van Horne, J. (2010). Fundamentos de administración financiera. México: Pearson Educación. 